\title{
Schizophrenia-Like Psychosis and Dandy-Walker Variant Comorbidity: Case Report
}

\author{
Selma Bozkurt Zincir $\bowtie$, Yiğit Kıvılcım, Filiz İzci, and Umit Basar Semiz \\ Erenkoy Training and Research Hospital for Psychiatric and Neurological Disorders, Istanbul, Turkey
}

\begin{abstract}
Dandy-Walker variant is a developmental malformation consisting of cerebellar hypoplasia and cystic dilatation of the fourth ventricle. Previous research has proposed a possible role for the cerebellum in cognition and in schizophrenia. In this paper we report a schizophrenia-like psychotic disorder in a 30 year-old woman with Dandy-Walker variant. The patient was treated with risperidone $6 \mathrm{mg} / \mathrm{day}$, biperiden $4 \mathrm{mg} /$ day and risperidone depot $50 \mathrm{mg}$ injections fortnightly, and most of the symptoms were ameliorated within 2 months. The similar cognitive profile to populations with cerebellar pathology and rarity of the condition strongly suggests that there may be direct relationship between cerebellar pathology and appearence of psychotic symptoms.

Psychiatry Investig 2014;11:102-104
\end{abstract}

Key Words Schizophrenia, Dandy-Walker, Cerebellum, Comorbidity.

\section{INTRODUCTION}

Dandy Walker 'syndrome' was first defined by Dandy and Blackfan ${ }^{1}$ in 1914, but the its precise characteristic properties described by Hart et al. ${ }^{2}$ in 1972 . Dandy-Walker complex (DWC) is a series of neurodevelopmental anomalies in the posterior fossa, including Dandy-Walker malformation, Dandy-Walker variant (cerebellar hypoplasia and cystic dilatation of the fourth ventricle), mega-cisterna magna and posterior fossa arachnoid cyst. ${ }^{3}$ Although these four subtypes of DWC are believed to occur between the 7th and 10th week of gestation and are regarded as a continuum in embryology, they anatomically have their own unique characteristics. ${ }^{3}$ There are some rare case reports on coincidence of schizophrenia and DWC in medical literature, ${ }^{5-9}$ but the relationship between psychiatric symptoms and the DWC is still unclear because of the lack of data. Cerebellum plays an important role in cognition and a variety of psychiatric disorders ${ }^{10,11}$ including schizophrenia. ${ }^{12}$ Neuroimaging studies showing abnormalities

Received: January 23, 2013 Revised: April 30, 2013

Accepted: May 9, 2013 Available online: January 21, 2014

$\triangle$ Correspondence: Selma Bozkurt Zincir, MD, PhD

Erenkoy Training and Research Hospital for Psychiatric and Neurological Disorders, 19 Mayıs Mah. Sinan Ercan Cad. No: 29 Kazasker Kadıkoy, 34736 Istanbul, Turkey

Tel: +902163025959 , Fax: +902163560496

E-mail: sbozkurtzincir@yahoo.com

(a) This is an Open Access article distributed under the terms of the Creative Commons Attribution Non-Commercial License (http://creativecommons.org/licenses/bync/3.0) which permits unrestricted non-commercial use, distribution, and reproduction in any medium, provided the original work is properly cited. in cerebellar structure ${ }^{13}$ and function, especially the vermis, suggest the possible role of cerebellum in the pathophysiology of schizophrenia. These abnormalities can be detected both in chronic patients and at the time of onset of the disorder. ${ }^{13,14}$

Here we report a case of schizophrenia in a 30-year-old woman with Dandy Walker variant. The documentation of this case may contribute to the understanding of the pathophysiology of schizophrenia.

\section{CASE}

30-year-old female patient with a 2-year history of psychosis presented with schizophrenia-like symptoms including, auditory and visual hallucinations, sense of insecurity, delusions of reference, of persecution, of being controlled; inapropriate and labile affect; irritability, aggression, workplace absenteeism, sleep disruption, and having suicidal and homicidal thoughts was brought to the emergency department with her brother and sister. The patient was being followed in different outpatient clinics with irregular use of various psychotropic medications such as risperidone, olanzapine, sertraline etc. This was her first hospitalization. About two weeks before admission, she manifested strange behaviors (covering toilet windows with toothpaste, having a knife under the bed to sleep, occasionally trying to attack to relatives with a knife). Premorbid educational performance and social adjustment were reported as normal. Family history of psychosis in one of his brother was reported. No remarkable anomaly was found by physical 
examination and laboratory testing. The mental status examination revealed slowness of thought, stereotypic and vicious thought content, blunted affect, absence of spontaneous speech, psychomotor retardation, social withdrawal, poor rapport and lack of insight. Borderline intelligence activity was found on Weschler Adult Intelligence Scale-revised in Turkish (WAISRT) and full intelligence quotient was 75 . Her overall cognitive functions were obviously impaired; (poor attention, impaired recent and remote memory, visuospatial distortion, simple arithmetic) but the abstract reasoning was roughly good. Electroencephalogram revealed moderate bioelectric disorganization in each frontal and right temporooccipital regions and the presence of sharp wave discharges in the both centroparietal regions was reported. MR scanning disclosed cerebellar vermis hypoplasia and large cerebellar medullary system in the 4th ventricular posterior cisterna magna (keyhole deformity) that is compatible with Dandy-Walker variant (Figure 1). Initial treatment with Risperidone $50 \mathrm{mg}$ depot and $6 \mathrm{mg}$ /day p.o, biperiden $4 \mathrm{mg} /$ day p.o treatment and lorezepam $2.5 \mathrm{mg} /$ day p.o achieved nearly $35 \%$ reduction in Positive and Negative Symptoms Scale (PANSS) scores (from 144 to 90 ) within 10 days. Treatment with injectable risperi- done $50 \mathrm{mg}$ fortnightly eliminated positive psychotic symptoms and most of the negative symptoms within two months except social isolation.

\section{DISCUSSION}

In this case report, Dandy Walker variant and schizophrenia may be found coincidentally together or any cerebellar dysfunction due to Dandy Walker variant may cause or contribute to the appearance of psychotic symptoms. Considering previous case reports, psychiatric symptoms have been related with DWC but, the spectrum of mental symptoms varies quite widely between cases..$^{15}$ The varieties of structural abnormality of the brain in these cases might partly contribute to the diversity of the psychiatric symptoms since the position and the severity of the anomalies in the previously mentioned cases were not exactly the same. Despite the wide range of symptoms some common clinical features had been observed in a series of our cases: juvenile or young adult age onset, high frequency of family history of psychosis, atypical psychiatric symptoms, high prevalence of cognitive deficit, borderline intellectual functioning and refractoriness to treatment. ${ }^{15}$

Figure 1. Magnetic resonance images of the case demonstrates Dandy walker variant.
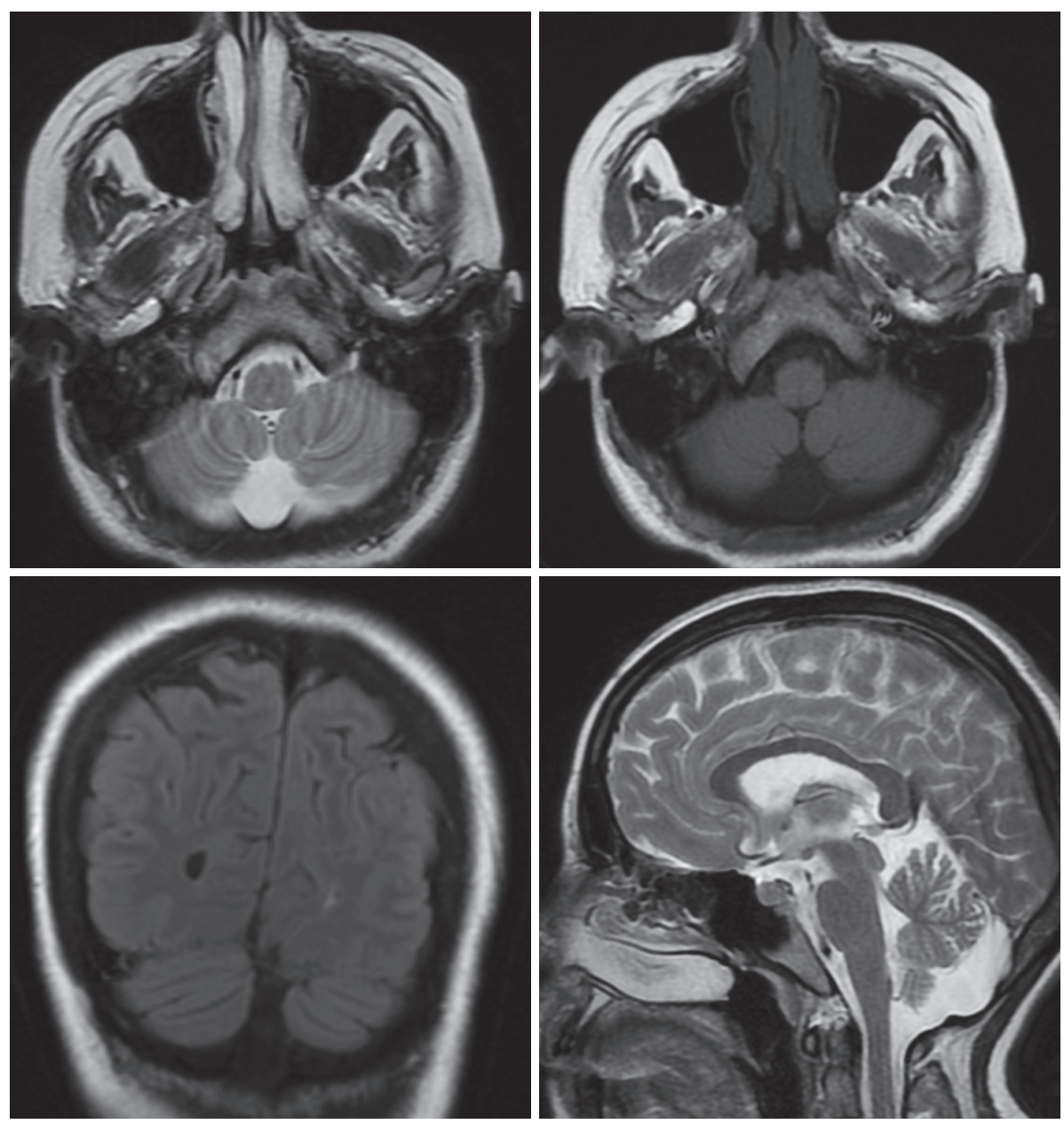
Most of these features were also found in the cases previously reported..$^{5-9}$

Andreasen suggested a model to explain "misconnections" between cortical regions and the cerebellum mediated through the thalamus in schizophrenia (the cortico-cerebellar-thalamic-cortical circuit). ${ }^{16}$ Psychotic symptoms such as hallucinations may occur in case of an abnormality in this circuit. ${ }^{17}$ It is also considered that cerebellar feedback pathways through the thalamus to the cerebral cortex may play a role in peduncular hallucinations. ${ }^{18,19}$ Some postmortem and neuroimaging studies have demonstrated cerebellar gray matter volume reduction and a smaller anterior vermis in schizophrenic patients relative to normal or psychiatric control subjects. ${ }^{20}$ There was a significant negative correlation between cerebellar gray matter volume reduction and halucinations. ${ }^{18}$ Moreover, in a study it was found that there was a significant correlation between delusions and activation of cerebellum. ${ }^{19}$

In the present case, Dandy Walker variant might contribute to the activation of cerebellum. In the light of these findings, it might be suggested that cerebellar dysfunction may interfere in the emergence of psychotic symptoms such as hallucinations and delusions.

\section{REFERENCES}

1. Dandy WE, Blackfan VD. Internal hydrocephalus. Am J Dis Child 1914; 8:406-482.

2. Hart MN, Malamud N, Ellis WG. The Dandy-Walker syndrome. A clinico-pathological study based on 28 cases. Neurology 1972;22:771780 .

3. Barkovich AJ, Kjos BO, Norman D, Edwards MS. Revised classification of posterior fossa cysts and cystlike malformations based on the results of multiplanar MR imaging. Am J Roentgenology 1989;153:1289-1300.

4. Utsunomiya H, Yamashita S, Takano K, Ueda Y, Fujii A. Midline cystic malformations of the brain: imaging diagnosis and classification based on embryologic analysis. Radiat Med 2006;24:471-481.

5. Turner SJ, Poole R, Nicholson MR, Ghadiali EJ. Schizophrenia-like psychosis and Dandy--Walker variant. Schizophr Res 2001;48:365-367.

6. Papazisis G, Mastrogianni A, Karastergiou A. Early-onset schizophre- nia and obsessive-compulsive disorder in a young man with DandyWalker variant. Schizophr Res 2007;93:403-405.

7. Turan T, Besirli A, Asdemir A, Ozsoy S, Esel E. Manic episode associated with mega cisterna magna. Psychiatry Investig 2010;7:305-307.

8. Prakash R, Singh LK, Kour J, Mishra B, Lakra A. Psychiatric comorbidities in Dandy-Walker variant disorder. J Neuropsychiatry Clin Neurosci 2009;21:477-479.

9. Ferentinos PP, Kontaxakis VP, Havaki-Kontaxaki BJ, Paplos KG, Pappa DA, Soldatos CR. Refractory psychosis and prominent cognitive deficits in a patient with mega-cisterna magna. Prog Neuropsychopharmacol Biol Psychiatry 2007;31:561-563.

10. Schmahmann JD. An emerging concept. The cerebellar contribution to higher function. Arch Neurol 1991;48:1178-1187.

11. Schmahman JD. Disorders of the cerebellum: ataxia, dysmetria of thought, and the cerebellar cognitive affective syndrome. J Neuropsychiatry Clin Neurosci 2004;16:367-378.

12. Martin P, Albers M. Cerebellum and schizophrenia: a selective review. Schizophr Bull 1995;21:241-250.

13. Ichimiya T, Okubo Y, Suhara T, Sudo Y. Reduced volume of the cerebellar vermis in neuroleptic-naive schizophrenia. Biol Psychiatry 2001; 49:20-27.

14. DeLisi LE, Sakuma M, Tew W, Kushner M, Hoff A, Grimson R. Schizophrenia as a chronic active brain process: a study of progressive brain structural change subsequent to the onset of schizophrenia. Psychiatry Res 1997;74:129-140.

15. Gan Z, Diao F, Han Z, Li K, Zheng L, Guan N, et al. Psychosis and Dandy-Walker complex: report of four cases. Gen Hosp Psychiatry 2012;34: 102.e7-102.e11.

16. Andreasen NC, O'Leary DS, Cizadlo T, Arndt S, Rezai K, Ponto LL, et al. Schizophrenia and cognitive dysmetria: a positron-emission tomography study of dysfunctional prefrontal thalamic cerebellar circuitry. Proc Natl Acad Sci U S A 1996;93:9985-9990.

17. Andreasen NC. A unitary model of schizophrenia: Bleuler's "fragmented phrene" as schizencephaly. Arch Gen Psychiatry 1999;56:781787.

18. Neckelmann G, Specht K, Lund A, Ersland L, Smievoll AI, Neckelmann $\mathrm{D}$, et al. Mr morphometry analysis of grey matter volume reduction in schizophrenia: association with hallucinations. Int J Neurosci 2006; 116:9-23.

19. Manford M, Andermann F. Complex visual hallucinations. Clinical and neurobiological insights. Brain 1998;121:1819-1840.

20. Weinberger DR, Kleinman JE, Luchins DJ, Bigelow LB, Wyatt RJ. Cerebellar pathology in schizophrenia: A controlled postmortem study. Am J Psychiatry 1980;137:359-361. 